\title{
Pharmacokinetic-Based Chemotherapy Dosing in Advanced Head and Neck Cancer: A Mini Review
}

\author{
Abdelhamid M. Fouad ${ }^{1}$, Ahmed Abo Gabal ${ }^{2}$, Mariam M. Elhaddad ${ }^{3}$ \\ ${ }^{1}$ Department of Medical Oncology, National Cancer Institute, Cairo University, Cairo, Egypt; \\ ${ }^{2}$ Department of Radiation Oncology, National Cancer Institute, Cairo University, Cairo, Egypt; \\ ${ }^{3}$ Department of Clinical and Chemical Pathology, National Cancer Institute, Cairo University, Egypt
}

Despite the continuous evolution in different treatment modalities for head and neck cancer (HNC), severe side effects of medications remain a challenge. Chemotherapy $(\mathrm{CTH})$-induced toxicities may lead to alterations in the treatment plan in the form of dose reduction, treatment delay or even discontinuation of treatment. Many efforts were done to overcome the impact of CTH-induced toxicity on HNC treatment. One of the explored strategies is the pharmacokinetic (PK)-based dosing of CTH.

A literature search for trials investigating PK-based CTH dosing in HNC from 1988 to 2018 was performed. Few clinical studies including one randomized clinical trial were identified. The limited evidence obtained from these studies shows that PK-based CTH dosing in HNC results in significantly less toxicities with no detrimental impact on treatment outcome.

The current evidence is not enough to recommend the routine use of PK-based CTH dosing in HNC. However, the promising results call for future studies.

Keywords: Pharmacokinetics, Chemotherapy, Toxicity, Head and neck cancer, Body surface area

Corresponding author: Abdelhamid M. Fouad, MD; National Cancer Institute, Cairo University, Cairo, 11795, Egypt; Email: abdelhamid.fouad@nci.cu.edu.eg

Submitted: 2-March-2019, Revised: 19-March-2019, Accepted: 25-March-2019, Published online: 1-May-2019

\section{INTRODUCTION}

Induction chemotherapy (CTH) in stage III and IV head and neck cancer (HNC) resulted in better response rate and survival; but, unfortunately, it was associated with increased toxicity. Severe (grade III and IV) hematological toxicity is one of the most common reported side effects of induction $\mathrm{CTH}$ in $\mathrm{HNC}^{1,2}$. Chemotherapy-related toxicities may significantly affect the treatment outcomes as it might lead to $\mathrm{CTH}$ delay, reduction of the scheduled total number of cycles or affect the patient's chance of completing his subsequent radical chemo-radiotherapy course successfully without interruptions ${ }^{3}$.

Pharmacokinetic (PK)-based dose adjustment of $\mathrm{CTH}$ had been assessed in a number of studies with the aim of improving therapeutic outcome and lowering toxicity profile and the results were promising ${ }^{3-6}$. However, to date, body surface area dosing remains the standard of care whenever CTH is prescribed ${ }^{7}$.

This review addresses the value of PK-based CTH dosing in advanced HNC.

\section{REVIEW OF LITERATURE}

A search of online databases was done using the search words "advanced head and neck cancer," "chemotherapy," and "pharmacokinetics". We included in this review peer-reviewed studies published in English from 1988 to 2018. Four studies were included and summarized in table 1.

In 1989, Santini et al published the results of their study which assessed the therapeutic monitoring of 5fluorouracil (5-FU) with dose adjustment in $\mathrm{HNC}^{3}$. One hundred and seventy cases with HNC (all were squamous cell carcinoma) received induction $\mathrm{CTH}$ divided into two groups. The first group $(n=89)$ represented a retrospective study which was based on the measurement of the concentration of 5-FU in blood systemically every cycle for 177 cycles. The aim of group 1 study was to aid in comparing the area under the curve (AUC) distribution values in tolerating treatment and response to disease. The second group $(n=81)$ prospective study included 249 cycles in which the dose was modified based on the data obtained from the first group study. The PK analysis of the first group revealed that the AUC for half cycle and the entire cycle reflected the cycle toxicity. Reducing the dose during the second half of the cycle for cases of the second group was based on real-time analysis and measurement of AUC during half cycle. Doses were reduced in $40 \%$ of the cycles during the second half of the course. There was a significant difference in the complete response rates between group 1 and group 2 (31\% and 47\%, respectively) with a $\mathrm{p}$ value $<0.05$. In addition, a significant difference in high grade toxicities was observed between the two groups in favor of group 2 (grade 3-4 toxicity was $20 \%$ in group 1 vs. $12.4 \%$ in group 2, p<0.05). 
Table 1: Studies that investigated the role of pharmacokinetic-based chemotherapy dosing in head and neck cancer

\begin{tabular}{|c|c|c|c|}
\hline Author (year) & Sample size & Study design & Outcome \\
\hline Santini et al (1989) ${ }^{3}$ & 170 & $\begin{array}{l}\text { Group } 1(n=89) \text { : retrospective PK } \\
\text { analysis of } 177 \text { cycles of 5-FU to } \\
\text { compare the AUC distribution as a } \\
\text { function of response \& tolerance. } \\
\text { Group } 2(n=81) \text { : prospective analysis of } \\
249 \text { cycles of } 5 \text {-FU in which the dose was } \\
\text { modified according to the results of } \\
\text { group } 1 .\end{array}$ & $\begin{array}{l}\text { Complete response rate: significantly higher } \\
\text { in group } 2(47 \%) \text { than in group } 1(31 \%) \text {, } \\
(\mathrm{p}<0.05) \text {. } \\
\text { Incidence of toxic cycles: significantly } \\
\text { lower in group } 2(12.4 \%) \text { than in group } 1 \\
(20 \%),(p<0.05) \text {. }\end{array}$ \\
\hline Fety et al (1998) ${ }^{4}$ & 122 & $\begin{array}{l}\text { Randomized clinical trial including two } \\
\text { arms: } \\
\text { - } \quad \text { Standard arm }(n=61) \text { : BSA- } \\
\text { based 5-FU dosing } \\
\text { - } \quad \text { PK arm }(n=61): 5-F U \text { dose } \\
\text { adjustment according to AUC 0- } \\
48 \mathrm{~h}\end{array}$ & $\begin{array}{l}\text { Grade } 3-4 \text { neutropenia \& } \\
\text { thrombocytopenia: significantly lower in } \\
\text { PK arm than standard arm ( } 7.6 \% \text { vs. } 17.5 \% \text {, } \\
\mathrm{p}=0.013) \\
\text { Grade } 3-4 \text { mucositis: significantly lower in } \\
\text { PK arm than standard arm ( } 0 \% \text { vs. } 5.1 \%, \mathrm{p} \\
<0.01) \\
\text { Objective response rate: no significant } \\
\text { difference between the two arms }\end{array}$ \\
\hline ten Tije et al (2005) ${ }^{5}$ & 51 & $\begin{array}{l}\text { Prospective study comparing PK of } \\
\text { docetaxel in } 25 \text { elderly }(\geq 65 \text { years) vs. } \\
26 \text { younger ( }<65 \text { years) cancer patients } .\end{array}$ & $\begin{array}{l}\text { No significant difference in docetaxel PK } \\
\text { between the two groups. } \\
\text { Non-significant higher rate of grade } 4 \text { and } \\
\text { febrile neutropenia in the elderly group }\end{array}$ \\
\hline Fouad et al $(2018)^{6}$ & 39 & $\begin{array}{l}\text { Prospective study investigating PK-based } \\
\text { dosing of docetaxel and 5-FU in HNC } \\
\text { patients. }\end{array}$ & $\begin{array}{l}\text { PK-based dosing of docetaxel and 5-FU did } \\
\text { not result in an inferior outcome. } \\
\text { PK-based dosing associated with } \\
\text { significantly less CTH -related toxicity and } \\
\text { death. }\end{array}$ \\
\hline
\end{tabular}

PK: Pharmacokinetic, 5-FU: 5-Fluorouracil, BSA: Body surface area, AUC: Area under the curve, CTH: Chemotherapy, HNC: Head and neck cancer

One randomized multicenter study conducted by Fety et al investigated the outcome of adjusting the dose of 5-FU according to PKs in advanced HNC patients ${ }^{4}$. One-hundred and twenty-two patients with HNC randomly received platinol and 5-FU protocol according to their body surface area (BSA) (standard group) or PKbased dosing (PK group). Grade 3-4 toxicities were higher in the standard group $(17.5 \%)$ in comparison to the PK group (7.6\%) and the difference was statistically significant $(\mathrm{p}=0.013)$. The objective response rate was more or less the same in the two groups. The investigators concluded that PK dose adjustment can result in reducing treatment related toxicities without compromising the treatment efficiency and the response rate $^{4}$.

ten Tije et al prospectively assessed the impact of docetaxel PK on toxicity profile in 51 cancer patients. Twenty-five were elderly ( $\geq 65$ years) and 26 were younger patients $(<65$ years $){ }^{5}$. In this study, the dose of docetaxel administered was $75 \mathrm{mg} / \mathrm{m}^{2}$ every 21 days. Pharmacokinetic analysis and monitoring of side effects took place during the first cycle of treatment. They found that docetaxel PKs didn't differ significantly between elderly patients and younger patients. Although statistically non-significant, the rate of docetaxel-related myelosuppression was higher in the group of elderly patients ${ }^{5}$.
A recent prospective study was conducted by Fouad et al to evaluate the outcome of treating advanced HNC patients with docetaxel and 5-FU using doses based on PKs ${ }^{6}$. The study included 39 patients (all with stage III and IV HNC). The patients were started on neoadjuvant $\mathrm{CTH}$ protocol including docetaxel, cisplatin and 5-FU (DPF). During the first cycle, doses of all the 3 chemotherapeutic agents were based on BSA. With the beginning of the second cycle, the doses of docetaxel and 5-FU were adjusted based on PK whereas cisplatin dose was not modified and was based on BSA throughout the study. After a median follow up period of 14 months, the estimated overall survival was 15.1 months and progression free survival was 10.6 months. During the evaluation of response, 29 patients were assessed. Percentage of patients who achieved complete response was $23.3 \%$ of the assessed cases (7 patients) whereas the percentage of patients with partial response was $66.7 \%$ (20 patients) with overall response rate of $89.6 \%$. Obviously, there was significant reduction in CTH-induced toxicities $(p=0.007)$ and deaths $(p=0.01)$ after the modification of doses of docetaxel and 5-FU according to PK. The authors concluded that the treatment outcome obtained with PK-based dose modification of docetaxel and 5-FU in the DPF protocol is not inferior to that obtained with BSA-based dosing. Furthermore, PK-based dosing was associated with better tolerance to treatment and less serious toxicities ${ }^{6}$. 


\section{CONCLUSIONS}

The studies that evaluated PK-based $\mathrm{CTH}$ administration in advanced HNC showed encouraging results in improving response and lowering toxicity. However, further research is needed for better evaluation of this promising approach.

\section{REFERENCES}

1. Vermorken JB, Remenar E, van Herpen C, et al. Cisplatin, fluorouracil, and docetaxel in unresectable head and neck cancer. N Engl J Med. 2007; 357(17): 1695-1704.

2. Posner MR, Hershock DM, Blajman CR, et al. Cisplatin and fluorouracil alone or with docetaxel in head and neck cancer. N Engl J Med. 2007; 357(17): 1705-1715.

3. Santini J, Milano G, Thyss A, et al. 5-FU therapeutic monitoring with dose adjustment leads to an improved therapeutic index in head and neck cancer. Br J Cancer. 1989; 59(2): 287-290.

4. Fety R, Rolland F, Barberi-Heyob M, et al. Clinical impact of pharmacokinetically-guided dose adaptation of 5- fluorouracil: results from a multicentric randomized trial in patients with locally advanced head and neck carcinomas. Clin Cancer Res. 1998; 4(9): 2039-2045.

5. ten Tije AJ, Verweij J, Carducci MA, et al. Prospective evaluation of the pharmacokinetics and toxicity profile of docetaxel in the elderly. J Clinl Oncol. 2005; 23(6): 10701077.

6. Fouad AM, Saber MM, Isamil YM, et al. Treatment outcome of pharmacokinetics-based dosing of docetaxel and fluorouracil in advanced head and neck cancer patients. J Cancer Ther. 2018; 9: 998-1010.

7. Du Bois D, Du Bois EF. A formula to estimate the approximate surface area if height and weight be known. 1916. Nutrition. 1989; 5(5): 303-311; discussion 312-313. 